\title{
Technology and Learning Base for Sustainable Energy Conservation
}

\author{
Chavipa Phongthanachote ${ }^{1}$ and Ratthasak Phommas, ${ }^{\mathrm{a}, *}$ \\ ${ }^{1}$ Rattanakosin College for Sustainable Energy and Environment (RCSEE) Rajamangala University of \\ Technology Rattanakosin, 96 moo 3 Puthamonthon Sai 5, Salaya, Puthamonthon, \\ Nakhon Pathom, 73170, Thailand \\ chavipa007@gmail.com \\ ${ }^{*}, 2$ Department of Mechanical Engineering, Faculty of Engineering, Rajamangala University of Technology \\ Rattanakosin, 96 moo 3 Puthamonthon Sai 5, Salaya,Puthamonthon,Nakhon Pathom, 73170, Thailand. \\ ratthasak.pro@rmutr.ac.th
}

\begin{abstract}
The aim of energy conservation design is to provide two types of sustainability in terms of important energy topics: eco-friendly technology and eco-friendly humanity through building awareness from childhood. Most research concerns technology design such as electrical appliances for energy saving, but the research that will be discussed is to build awareness for technology users by creating awareness in children from the age of 7-12 years old, covering elementary school grades 1-6. This is suitable for elementary school students according to Skinner's theory of learning.
\end{abstract}

Keywords: Energy conservation, Awareness, Program learning

\section{Introduction}

A lack of awareness about energy conservation within society leads to energy wastage. Earlier research indicates that there was one conservation method which attracted the most attention, and that was energyefficient technology. Today, however, it is believed that eco-friendly human behavior may be more important if energy is to be conserved. While the technological approach is based on tools or equipment, the human approach requires changes in behavior through motivational strategies, awareness building, and the development of the necessary skills (Choong Weng Wai, Abdul Hakim Mohammed \& Buang Alias, 2010). The structure of this study was therefore based on the theoretical approach to raising awareness of energy conservation.

1.1 Eco-friendly technology is the term applied to any technological means of saving energy. This can involve automation, new equipment which changes the way processes are carried out, or the implementation of large scale projects designed to save energy, such as heat recovery systems, or entire buildings constructed to be energy efficient. Technology can be an excellent means of conserving energy, and gains are often clearly visible in the short term. However, the drawback is that technology in many cases only offers a temporary solution. Technology can save energy, but this does not stop humans using more energy than is necessary, and thus the energy shortage problem is not addressed (Kempton \& Schipper, 1994). Technology imposes no requirement upon the user to change their behavior, so users will continue to behave in a wasteful manner, and this explains why technological solutions are only effective as short-term measures. To be successful in the long term, it is necessary to change people's behavior.

1.2 Eco-friendly human behavior is a term given to the actions of people in conserving energy. It is achieved through motivation people, increasing their awareness, and giving them the skills and knowledge to change their behavior. One study in Bangladesh showed that by altering behavior, electrical savings could be made amounting to $390 \mathrm{GWh}$ monthly, which is an annual rate of 4,683 GWh. The approach used was a bottom-up method, and the study confirms not only that behavioral changes can lead to energy savings, but also that those savings can reach from 3\% to 20\% (Halder \& Khan, 2016).

In studying the relationship between knowledge, attitudes, and energy consumption in the home, the group of people living in the house begin to save energy. A survey of attitudes about energy saving techniques was used as a sample to find out if people have a negative attitude about energy conservation or use less energy. The study of the development of conscious energy saving programs is carried out in accordance with the principles of learning through social services. For grade six students, it can be seen that the consciousness of energy saving stands at around $90 \%$, while level of critical reaction is about $10 \%$. After joining the program, the students had an average level of knowledge about energy saving methods which was higher than before joining the program (Maneesam, 2006). Therefore, in addition to using technology to save energy, it is important to focus on human behavior for effective energy conservation. The Energy Efficiency Office (1993) noted that to save energy it is necessary to motivate people to change their behavior. Wong (1997) makes the point that behavioral changes follow awareness, and therefore if behavior is to be changed, the strategy must begin with creating awareness. Energy awareness will therefore be defined and discussed in greater depth in the following section. 


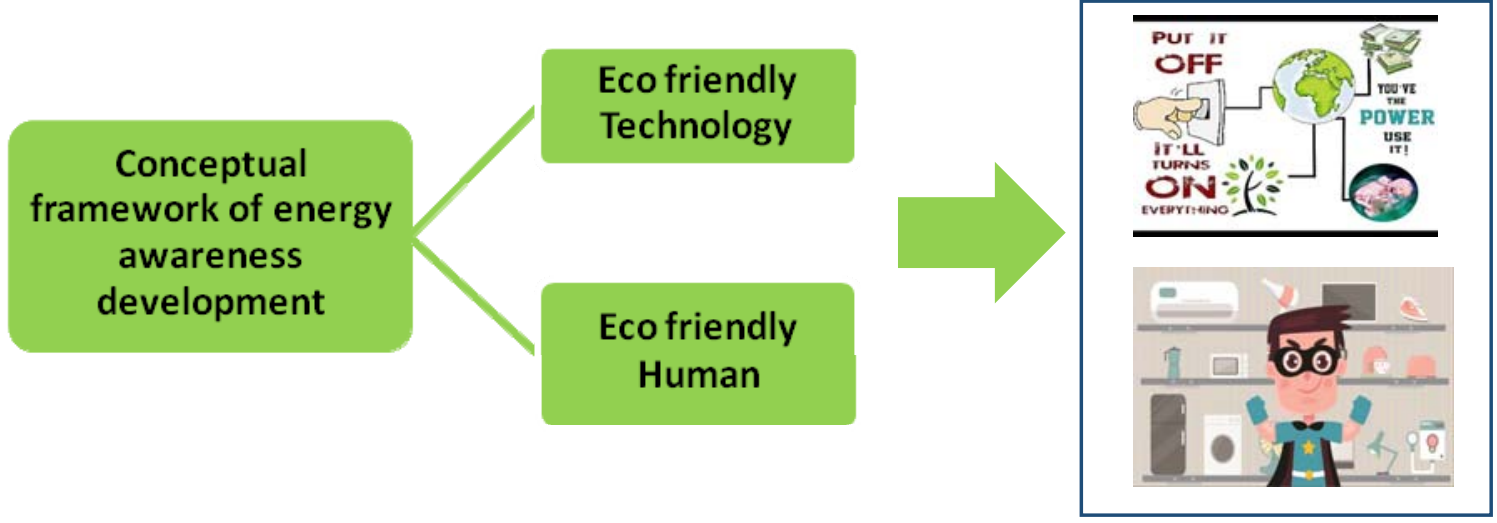

Figure 1. Awareness is needed to change attitudes to develop eco-friendly human behavior

\section{Energy Awareness}

To build awareness about energy saving requires B.F. Skinner's theory of learning and Edward L. Thorndike's law of exercise or repetition.

B.F Skinner: The Operant Conditioning Theory by Skinner in the 1950s in the United States was caused by critical lack of effective teachers. He thought of teaching aids to improve the education system, introducing the Program Instruction or Program Learning and Teaching Machine. Skinner's theory of learning and operant conditioning holds that there is a relationship between behavior and the environment. That is, the effect of the behavior influences the behavior, whereby the conditions will apply reinforcement. This is a very common technique used today. Following experimentation with animals in the laboratory, it was then found that the method can also work well with humans. Operant conditioning is the idea that the stimulus will produce consequences or effects.

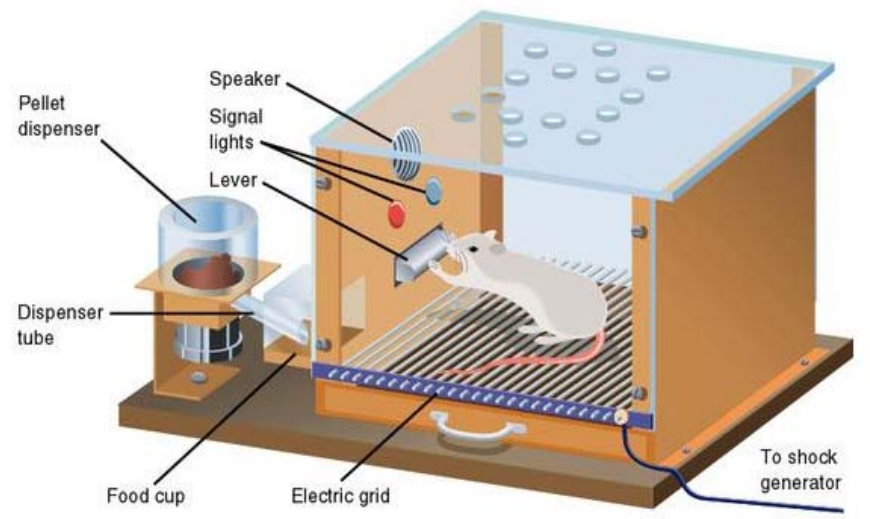

Figure 2. Skinner (1948) placed rats in a box to conduct experiments to develop the theory of operant conditioning

Edward L. Thorndike: Based on his experiments, the laws of learning are also called S-R learning. There are three basic laws of learning: the law of effect, the law of exercise, and the law of readiness. In this study, the principal focus will be the law of exercise, which holds first of all that the S-R connection becomes stronger when used but is made weaker when not used. Therefore, when an idea is used repeatedly, it is more likely to be well remembered. It is also the case that students will rarely learn difficult subject matter in one lesson. Instead, the instructor must repeat the key content at regular intervals to ensure it is retained. Therefore, there are three main ideas to follow:

1. The connection is firmer if it is used often but is weaker when not used.

2. Anything that is done repeatedly or is always practiced, will be done well. I do not like anything that has not been done for a long time.

3. Any behavior that has been done in the past will result in the completion of the action of the behavior. If there is no chance to use it, even often repeated actions are likely to be forgotten. Even if they are not forgotten, they cannot be completely corrected.

Furthermore, research studying the habits of children found that if a child grows up to eight years, then the habits that are embedded in the child are difficult to change. This study therefore aims to develop awareness of energy conservation in children who are 7-12 years old. 


\section{How to Build Awareness}

This paper intends to bring animation and games as a form of Program Learning to build awareness in teaching children of elementary school grades 1-6 (aged 7-12 years).

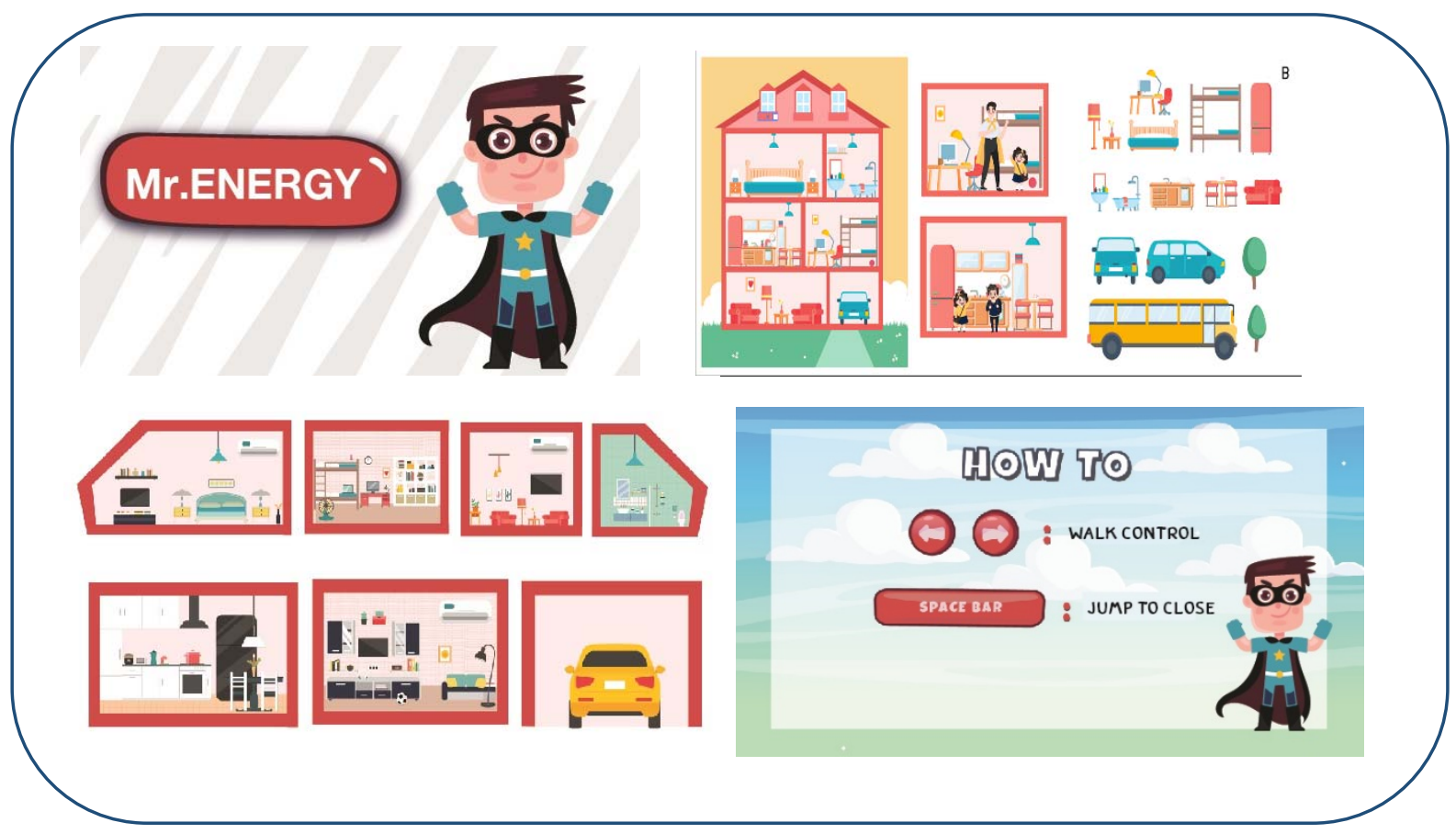

Figure 3. Animation and game "Awareness of Energy Conservation”

The "Awareness of Energy Conservation" is a form of program learning media that has been developed for students in the age range of 7-12 years using computer-aided learning. At present, the teaching is focused on the learners, and the nature of children is such that they will be interested in media focusing on animation and games. The researcher focuses on using the instructional media involving animation and games during elementary school to be taught continuously until the 6th grade. In the present time, we have seen more and more energy consumption, and as a result, a curriculum focusing on conserving energy and the environment has been developed at Kulno School, Phimai District, Nakhon Ratchasima Province. The sample participants were 35 grade six students selected by using purposive sampling. The evaluation consisted of four areas. First, the development of a curriculum focusing on the conservation of energy and the environment included 4 units. The statistical tools were used to analyze by considering the mean, standard deviation, and t-test. The results showed that as expected, after following the curriculum, the students had greater knowledge and awareness of the conservation of energy and the environment after training at the 0.05 level of significance (Jiwwiset, 2011).

In a review of the relevant literature by Moijue Kaikai and Erin Baker, it was reported that there are very few SEE investigations, although a small number do examine some of the SEE sub-categories observed in high schools. These can be considered as SEE elements, and in particular they can be described as the aspects of education which provide students with the awareness and motivation necessary to work towards solutions to global sustainability in terms of energy usage.

Furthermore, Schelly et al. (2012) made the point that one factor which can cause people to change their energy usage behavior is a better understanding of the economic impact their habits create, as well as the harmful environmental impact of their energy usage. It is noted that energy conservation measures can readily be employed in public schools, which would be able to alter their behavior to cut energy consumption by up to $30 \%$ through implementing various operational changes. The results of the study of Schelly et al. (2012) suggest that if schools provide educational activities which encourage students to examine their own energy usage more closely, the result is that these young learners may become role models in their communities. It was also observed that the schools and the administrators of learning institutions also became more environmentally aware and began to take steps to reduce their energy consumption when their students took the lead. These findings are supported by the work of Fujihira and Osuka (2009) who discovered that students who acquire knowledge about their own energy consumption are then in turn more capable of reducing that usage, as well as encouraging their communities to follow. In a similar study by Gottlieb et al. (2012), the students were invited to monitor their own ecological footprints, thereby becoming much more keenly aware of the impact of their energy consumption and the broader context of that consumption outside and beyond the narrow confines of their own communities. The use of methods such as those of Gottlieb et al. (2012) which relied on carbon 
footprint analysis could be used with SEE in schools to support the knowledge of learners and plan the changes required to achieve sustainability in the schools in the future.

\section{Conclusion}

The research that has been presented focuses on the program of instruction or Program Learning based on Skinner's theory learning and Edward L. Thorndike's theory. There are previous research results which have shown that the use of student-centered learning is more effective than normal study. A present, the way energy is managed is very important for every human on earth. Fundamentally, there are two ways to make energy savings: eco-friendly technology and eco-friendly human behavior. These methods can be applied in combination to achieve the best outcomes. Eco-friendly human behavior requires the building of awareness as the first step in modifying people's behavior to conserve energy. This is something which is most effective when the process begins in childhood. This study has therefore discussed the conceptual framework which would be applied in developing awareness to change behavior for sustainable energy consumption in the future.

\section{REFERENCES}

[1] Choong Weng Wai, Abdul Hakim Mohammed, And Buang Alias: Energy Conservation: A Conceptual Framework Of Energy Awareness Development Process, Department Of Property Management, Faculty Of Geoinformation Science And Engineering, Universiti Teknologi Malaysia, 81310 Skudai, Johor, Malaysia

[2] Cook, Carolann. (1996, September). Energy Conservation Behavior: Description and Analysis of the Energy Conservation Corps (Home Energy Audits) DAI-A 57/03, 972.

[3] Edgardo Esteban Agno (1980). A Proposed Model on Energy Education for National Development of the Philippines with Emphasis on the Planning and Implementation Roles of Vocational-Technical Education. The Florida State University: Degree of Doctor of Philosophy.

[4] Eysenck, H.I. \& W. Amold. (1972) Encyclopedia of Psychology. London: Search, Press Good, C.V. (1973). Dictionary of Education. 3 rd ed. New York: McGraw-Hill Book Company Krathwohl, D.R,B.S. Bloom \& B.B. Masia. (1956) Taxonomy of Education Objective - The Classification of Education Goals. Handbook II. Affective Domain. New York: Mc.Kay.

[5] Rohadi, Nyomanman \& Tayior, Peter C. (1992, December). The Need for Energy -Related Instruction in Indonesian Senior High School. Journal of Science and Mathematics Education in Southeast-Asia. p.33

[6] Smith, J. L. (1978). An Evaluation of A Model Energy Awareness and Conservation Inservice Program for Oklahoma Driver Education Teachers. Oklahoma State University: Degree of Doctor of Education.

[7] Stewart, Jey Newwitt. (1982, September). Relations Between Attitudes Knowledge and Construction and their effect on Residential Energy Consumption. Dissertation Abstract International. p.42

[8] https://elearningindustry.com/operant-conditioning-theory

[9] Thorndike, E. (1932). The Fundamentals of Learning. New York: Teachers College Press.

[10] Yukata Mizuta (2003). A Case Study On Energy Saving and New Energy Services in Japan. Management of Environmental Quality: An International Journal. 14(2): 214-220

[11] Mohamed G. Hassan , R. Hirst , C. Siemieniuch \& A.F. Zobaa. Determining energy saving behavior and energy awareness of secondary school students according to socio-demographic characteristics

[12] I. Khan*, P. K. Halder Electrical Energy Conservation through Human Behavior Change: Perspective in Bangladesh, Corresponding Author: P. K. Halder, Accepted: 29.12.2015

[13] Chanya Jiwwiset. (2011). Curriculum support activity on energy and environmental conservation: a case study of Kulno School, Nakhon Ratchasima province. Bangkok Thailand.

[14] Moijue Kaikai and Erin Baker; Engineering for Sustainable Energy Education within Suburban, Urban and Developing Secondary Schools; (2016) SAGE Publications (Los Angeles, London, New Delhi, Singapore, Washington DC and Melbourne) www.sagepublications.com Vol 10(1): 88-100

[15] Gottlieb, D., Vigoda-Gadot, E., Haim, A., \& Kissinger, M. (2012). The ecological footprint as an educational tool for sustainability: A case study analysis in an Israeli public high school. International Journal of Educational Development, 32(1), $193-200$.

[16] Fujihira, K., \& Osuka, K. (2009). An educational methodology for sustainable development. ICROS-SICE International Joint Conference 2009, ICCAS-SICE 2009, Fukuoka International Congress Center, Fukuoka, Japan, August 18, 2009-August 21, pp. $4266-4271$.

[17] Schelly, C., Cross, J.E., Franzen, W., Hall, P., \& Reeve, S. (2012). How to go green: Creating a conservation culture in a public high school through education, modeling, and communication. Journal of Environmental Education, 43(3), 143-161 